\title{
Discussion of Chau and Lo (2004): Hazard assessment of debris flow for Leung King Estate of Hong Kong by incorporating GIS with numerical simulations (Vol. 4, p. 103-116)
}

\author{
S. Parry ${ }^{1}$, M. E. Ruse ${ }^{2}$, and S. J. Williamson ${ }^{3}$ \\ ${ }^{1}$ Geotechnical Engineering Office, Civil Engineering and Development Department, Hong Kong, China \\ ${ }^{2}$ Fugro (Hong Kong) Ltd., Hong Kong, China \\ ${ }^{3}$ Maunsell Geotechnical Services Ltd., Hong Kong, China
}

Received: 5 August 2004 - Revised: 18 October 2004 - Accepted: 7 December 2004 - Published: 3 January 2005

\section{Introduction}

In their paper, Chau and Lo (2004) present a numerical model to assess debris flow hazard at Leung King Estate, Hong Kong. They applied a modified version of a flow dynamics model, developed by Takahashi et al. (1992), to review the possible impacts of a debris flow event to a residential area, using simplified site-specific and regional data. The paper is opportune as the geotechnical engineering community in Hong Kong is currently examining potential landslide risk from "natural terrain" in Hong Kong, and some discussion of methods and data is appropriate.

\section{Discussion}

Chau and Lo's (2004) stated aim is to promote "the sound theoretical approach in GIS-base (sic) hazard mapping, such that expert opinion can be reduced to a minimum", as "socalled expert opinions" are "bounded (sic) to be subjective and biased". This comment epitomises the commonly held but, in the Authors' opinion, misguided viewpoint that the numerical approach common in engineering is more accurate and therefore more scientific than the conceptual approach common to much of earth science.

In contrast, we would suggest that hazard assessment of debris flows requires a suite of analyses, including evaluation of the geology, morphology and process behaviour of the study area and its vicinity. These analyses allow the development of a conceptual geological model from which hazard models that incorporate landslide susceptibility of the terrain can be generated and finally allow the application of debris runout models. This approach was adopted for the recent landslide hazard study conducted for the Tsing Shan range, including Leung King Estate (Parry et al., 2002; Ruse et al., 2002). Such approaches can use inference, intuition, anal-

Correspondence to: S. Parry

(sparry@ netvigator.com) ogy or qualitative information; i.e. approaches Chau and Lo (2004) might consider "subjective and biased".

The second main issue arising from Chau and Lo (2004) is the accuracy of their data. We acknowledge that Chau and Lo (2004) state that their main focus is not the absolute accuracy of the hazard estimations, that their flow model may involve unwanted simplification and assumptions, and that "the details of the numerical simulation are not crucial". However, on the basis of their analysis, they conclude that debris could impact buildings to a height of two stories and that debris flow barriers should be installed to protect two schools and two residential towers in Leung King Estate. They also state that other approaches "do not necessarily yield reliable results compared to the flow-dynamics-based estimation". The validity of such conclusions depends substantially on the accuracy of the data and consequently a brief discussion is appropriate.

Chau and Lo (2004) acknowledge that a reliable landslide hazard map should consider historical and geomorphological data, but singularly fail to do so. The data Chau and Lo (2004) extracted from the volcanically-induced Mount St. Helens debris flow produces velocities two orders of magnitude greater than any reported values for landslides in Hong Kong, even when arbitrarily scaled down. Similarly the volume of failure utilized by Chau and Lo (2004) was nearly two orders of magnitude greater than the largest landslide interpreted in the area and approximately 200 times larger than the Leung King Estate debris flow of April 2000 that prompted their investigation. None of the landslide debris of April 2000 affected Leung King Estate, though the estate was affected by subsequent alluvial outwash (Halcrow, 2000) ${ }^{1}$. The potential for landslides to impact on the estate has been evaluated and four gabion check dams, based on design event

\footnotetext{
${ }^{1}$ Halcrow Asia: Detailed study of selected landslides above Leung King Estate of 14 April 2000, Landslide Study Report LSR 9/2001, Geotechnical Engineering Office, Civil Engineering Department, Government of Hong Kong SAR, 134, 2001 (unpublished but available in the Civil Engineering Library, Civil Engineering and Development Building, Ho Man Tin, Kowloon, Hong Kong).
} 
of $600 \mathrm{~m}^{3}$, were constructed in 2000 . As part of the subsequent Tsing Shan landslide study, the design assumptions at Leung King Estate were reviewed and considered to be appropriate to protect the Estate from future failures.

Chau and Lo's (2004) main contribution to the model of Takahashi et al. (1992) is to incorporate potential erosion and deposition using features such as relative settling velocities within a debris flow. We suggest that the nature of the substrate, particularly its entrainability, and detailed morphological variations of the drainage lines, such as the channelisation ratio and local slope gradient, which Chau and Lo (2004) do not adequately address, assume far greater importance to debris flow mobility than relative settling velocities.

The final issues relate to the comparison made with previous studies in Hong Kong. As the landslide susceptibility work of Evans et al. (1999) was based on a regional landslide dataset, the work states that it should not be used at a site-specific scale, such as for Leung King Estate. Furthermore, while Evans et al. (1999) state that their dataset shows no direct correlation between elevation and landsliding, Chau and Lo (2004) use elevation in their test of the "statistical approach". Finally, the work of Evans et al. (1999) was used for regional scale hazard map of initiation i.e. it does not incorporate debris runout, and consequently it is neither a risk map nor suitable for comparison with Chau and Lo's (2004) results.

Chau and Lo (2004) also compared their debris flow model with the Tsing Shan debris flow of 1990 (King, 2001). This comparison reemphasizes the problem of modelling with limited site-specific information. The 1990 debris flow is the largest recent debris flow in Hong Kong. Its large size was a direct result of its morphological setting. It initiated as a relatively small landslide, but substantially increased in volume because of momentum imparted by a significant break in slope and the presence of large amounts of entrainable material. In comparison, the Leung King area is morphologically quite different, with geological conditions that limit entrainment (Fletcher et al., 2002). The Chau and Lo (2004) approach does not recognize such important distinctions between the geological models and landslide hazard of the two areas.

\section{Conclusion}

Hazard assessment of debris flows is undoubtedly a complex matter. Use of numerical models is one potential component of an integrated approach, as emphasized by the guidelines for natural terrain hazard studies ( $\mathrm{Ng}$ et al., 2000). In contrast to Chau and Lo (2004), the present authors consider that the disadvantage of Chau and Lo's approach is that "it is based on dynamics, instead of expert opinions or on past debris flow records" (Chau and Lo, 2004). It is rather naive to think analytical tools can lead the study; in the authors' opinion, they are simply tools to be applied to natural terrain hazard studies, within the limit of current knowledge and suitable judgement. Chau and Lo's (2004) conclusion that numerical simulation results "must be incorporated" given their "sound theoretical background" is not supported by the case presented. We consider the use of numerical runout models to make recommendations for risk mitigation to be poor practice if the geological data and models are not sufficiently detailed, or are not either site-specific or site-appropriate. Hazard and risk analyses rely on the integration of a number of skills and approaches; numerical analyses form a substantial component, good judgment forms another.

The views expressed in this article are the personal views of the authors.

Edited by: F. Guzzetti

Reviewed by: A. Hansen and another referee

\section{References}

Chau, K. T. and Lo, K. H.: Hazard assessment of debris flows for Leung King Estate of Hong Kong by incorporating GIS with numerical solutions, Nat. Haz. Earth Sys. Sc., 4, 103-116, 2004, SRef-ID: 1684-9981/nhess/2004-4-103.

Evans, N. C., Huang, S. W., and King, J. P.: The Natural Terrain Landslide Study Phases I and II, GEO Report No. 73 Geotechnical Engineering Office, Civil Engineering Department, Hong Kong Special Administrative Region Government, 128 p. plus 2 drgs., 1999.

Fletcher, C. J. N., Massey, C. I., Williamson, S. J., and Parry, S.: Importance of bedrock and regolith mapping for natural terrain hazard studies: an example from the Tsing Shan area, Hong Kong. Natural Terrain - A Constraint to Development?, Institution of Mining and Metallurgy, Hong Kong Branch, 61-75, 2002.

King, J. P.: The 1990 Tsing Shan Debris Flow, in: Geotechnical Engineering: Meeting Society's Needs, edited by Ho, K. K. S. and Li, K. S., Proceedings of the $14^{\text {th }}$ South East Asian Geotechnical Conference, Hong Kong, 783-788, 2001.

Ng, K. C., Parry, S., King, J. P., Franks, C. A. M., and Shaw, R.: Guidelines for Natural Terrain Hazard Studies, GEO Report No. 138 Geotechnical Engineering Office, Civil Engineering Department, Hong Kong Special Administrative Region Government, 138, 2003.

Parry, S., Massey, C. I., and Williamson, S. J.: Landslide susceptibility analysis for natural terrain hazard studies - Tsing Shan Foothills. Natural Terrain - A Constraint to Development? Institution of Mining and Metallurgy, Hong Kong Branch, 113-123, 2002.

Ruse, M. E., Waring, D. P., Kaldy, A., Chan, S. K., and Ng, K. C.: Initiation and runout characteristics of a swarm of 121 landslides in the Tsing Shan Foothills, Hong Kong. Natural Terrain A Constraint to Development? Institution of Mining and Metallurgy, Hong Kong Branch, 77-87, 2002.

Takahashi, T., Nakagawa, H,. Harada, T., and Yamashiki, Y.: Routing debris flows with particle segregation, J. Hydr. Res., 118, 11, 1490-1507, 1992. 